\title{
ASO Author Reflections: Extracapsular Spread in Melanoma Lymphadenopathy: Prognostic Implications, Classification, and Management
}

\author{
Michelle Lo, MB, BS, MRCS ${ }^{1}$, Howard Peach, FRCS(Plast.) ${ }^{2}$, and Marc Moncrieff, MD, FRCS(Plast.) ${ }^{1,3} \mathbb{( 1 )}$ \\ ${ }^{1}$ Plastic and Reconstructive Surgery Department, Norfolk and Norwich University Hospital, Norwich, UK; ${ }^{2}$ Plastic \\ Surgery, Leeds Teaching Hospitals NHS Trust, Leeds, UK; ${ }^{3}$ Norwich Medical School, Faculty of Medicine and Health \\ Sciences, University of East Anglia, Norwich, UK
}

\section{PAST}

The current American Joint Committee on Cancer (AJCC) classification system for stage III cutaneous melanoma is heterogeneous, with 5-year melanoma-specific survival rates ranging from $88 \%$ for stage IIIA disease to $24 \%$ for stage IIID disease. Currently, the stage III classification not only incorporates data from the $\mathrm{N}$ stage, but also qualifies $\mathrm{T}$ data from the primary tumour such as Breslow thickness and ulceration status. This takes into account the fact that the risk of distant spread and subsequent death from melanoma for the stage III group is dependent on the risk of hematogenous spread from a deeply invading primary tumour, in addition to the disease burden of the metastatic nodes. Extracapsular spread (ECS), a well-known risk factor for locoregional recurrence in melanoma patients with macrometastatic disease, is associated with a poor prognosis. ${ }^{1-3}$ Although ECS is a biomarker for poor prognosis, it is not included in the current AJCC classification system.

\section{PRESENT}

This multi-center retrospective cohort study of 515 patients with nodal metastases ${ }^{4}$ comprehensively analyzed the clinical relevance of ECS as a biomarker in nodal

(C) The Author(s) 2020

First Received: 24 September 2020 Accepted: 24 September 2020; Published Online: 20 October 2020

M. Moncrieff, MD, FRCS(Plast.)

e-mail: marc.moncrieff@nnuh.nhs.uk disease and demonstrated that ECS is the most important prognostic indicator for both macroscopic and microscopic disease, upstaging patients to the next echelon in a manner comparable with ulceration of the primary. The authors have devised a simplified clinically and surgically relevant classification system for microscopic and macroscopic stage III disease by replacing $\mathrm{N}$ stage with ECS status.

\section{FUTURE}

Extracapsular spread was an exclusion criterion for the last two major phase 3 melanoma surgical trials, ${ }^{5,6}$ and the authors suggest that ECS in sentinel node-positive patients still may be an indication for lymphadenectomy to achieve regional control of disease as well as for adjuvant systemic therapy. In future versions of the AJCC guidelines, ECS should be considered as an independent staging variable pending further validation of its relevance.

OPEN ACCESS This article is licensed under a Creative Commons Attribution 4.0 International License, which permits use, sharing, adaptation, distribution and reproduction in any medium or format, as long as you give appropriate credit to the original author(s) and the source, provide a link to the Creative Commons licence, and indicate if changes were made. The images or other third party material in this article are included in the article's Creative Commons licence, unless indicated otherwise in a credit line to the material. If material is not included in the article's Creative Commons licence and your intended use is not permitted by statutory regulation or exceeds the permitted use, you will need to obtain permission directly from the copyright holder. To view a copy of this licence, visit http://creativecommons. org/licenses/by/4.0/.

\section{REFERENCES}

1. Henderson MA, Burmeister BH, Ainslie J, et al. Adjuvant lymphnode field radiotherapy versus observation only in patients with 
melanoma at high risk of further lymph-node field relapse after lymphadenectomy (ANZMTG 01.02/TROG 02.01): 6-year followup of a phase 3, randomised controlled trial. Lancet Oncol. 2015;16:1049-60.

2. Agrawal S, Kane JM III, Guadagnolo BA, Kraybill WG, Ballo MT. The benefits of adjuvant radiation therapy after therapeutic lymphadenectomy for clinically advanced, high-risk, lymph nodemetastatic melanoma. Cancer. 2009;115:5836-44.

3. Lee RJ, Gibbs JF, Proulx GM, Kollmorgen DR, Jia C, Kraybill WG. Nodal basin recurrence following lymph node dissection for melanoma: implications for adjuvant radiotherapy. Int $J$ Radiat Oncol Biol Phys. 2000;46:467-74.

4. Lo M, Robinson A, Wade R, et al. Extracapsular spread in melanoma lymphadenopathy: prognostic implications, classification, and management. Ann Surg Oncol. 2020. https://doi.org/10.1245/s104 34-020-09099-w.

5. Faries MB, Thompson JF, Cochran AJ, et al. Completion dissection or observation for sentinel-node metastasis in melanoma. N Engl J Med. 2017;376:2211-22.

6. Leiter U, Stadler R, Mauch C, et al. Complete lymph node dissection versus no dissection in patients with sentinel lymph node biopsy positive melanoma (DeCOG-SLT): a multicentre, randomised, phase 3 trial. Lancet Oncol. 2016;17:757-67.

Publisher's Note Springer Nature remains neutral with regard to jurisdictional claims in published maps and institutional affiliations. 